\title{
Effect of coffee agriculture management on the population structure of a forest dwelling rodent (Heteromys desmarestianus goldmani)
}

\author{
Beatriz Otero-Jiménez ${ }^{1,2}\left(\right.$ D John H. Vandermeer ${ }^{1} \cdot$ Priscilla K. Tucker $^{1,2}$
}

Received: 24 February 2017 / Accepted: 19 September 2017 / Published online: 9 October 2017

(C) The Author(s) 2017. This article is an open access publication

\begin{abstract}
Most of the natural habitat in tropical regions exists as scattered fragments embedded in a matrix of different agricultural uses. As a result of this agricultural expansion, habitat loss and fragmentation have become the main drivers of biodiversity loss. Understanding the long-term effects of agricultural management on populations is of great importance for the development of successful conservation strategies. Our study uses genetic data to determine the effect of agricultural management practices on the population structure of a common tropical forest rodent (Heteromys desmarestianus goldmani). We sampled 136 individuals from one forest fragment and three coffee farms representing varying degrees of management intensity in southern Mexico. Using microsatellite markers, we evaluated the genetic structure of $H$. $d$. goldmani in the study area. Our results show higher genetic differentiation and lower connectivity for individuals within high and medium intensity coffee farms than for those near and within the forest fragments. Our results suggest that the population structure observed is driven by landscape characteristics other than distance.
\end{abstract}

Keywords Small mammal $\cdot$ Agriculture $\cdot$ Matrix $\cdot$ Landscape genetics

\section{Introduction}

Agricultural production is expanding at rapid rates in the tropics. As a consequence, most tropical forests exist as fragments embedded within a mosaic of agricultural land (Perfecto and Vandermeer 2008). Organisms that inhabit these landscapes must be able to persist within agricultural lands or navigate through them to reach habitable patches (Levins 1969). Therefore, the development of successful conservation strategies requires an understanding of the effect of agricultural production and intensification on population persistence. Agricultural intensification is the transition from traditional production systems (e.g., crop

Electronic supplementary material The online version of this article (https://doi.org/10.1007/s10592-017-1016-9) contains supplementary material, which is available to authorized users.

Beatriz Otero-Jiménez

botero@umich.edu

1 Department of Ecology and Evolutionary Biology, University of Michigan, 2019 Kraus Nat. Sci. Bldg., 830 North University, Ann Arbor, MI 48109-1048, USA

2 Museum of Zoology, University of Michigan, 1109 Geddes Ave, Ann Arbor, MI 48109, USA rotation, polycultures) to systems with industrial management practices (e.g., monocultures, use of agrochemicals) (Perfecto et al. 2009). For example, coffee production in Latin America falls along an intensification gradient ranging from rustic polyculture to unshaded monocultures (Moguel and Toledo 1999; Fig. 1a). This has made coffee production a model system for studies of the effects of agricultural intensification on biodiversity. Studies in coffee agroecosystems have shown a decrease in biodiversity as agricultural management intensity increases for many species, such as ants, birds, trees, bees, and bats (Perfecto and Vandermeer 2015). Less is known about the effects that management practices have on the dispersal and gene flow of species in this system.

Recently, with the development of new molecular techniques, indirect measures of dispersal can be used for studies of population connectivity (Manel et al. 2003). Gene flow can decrease with fragmentation, generating population structure within a species and increasing the impact of genetic drift (Frankel and Soulé 1981). With genetic measurements, we can evaluate the negative effects of land use change and fragmentation (e.g., loss of genetic diversity, increased differentiation) (Manel et al. 2003). 

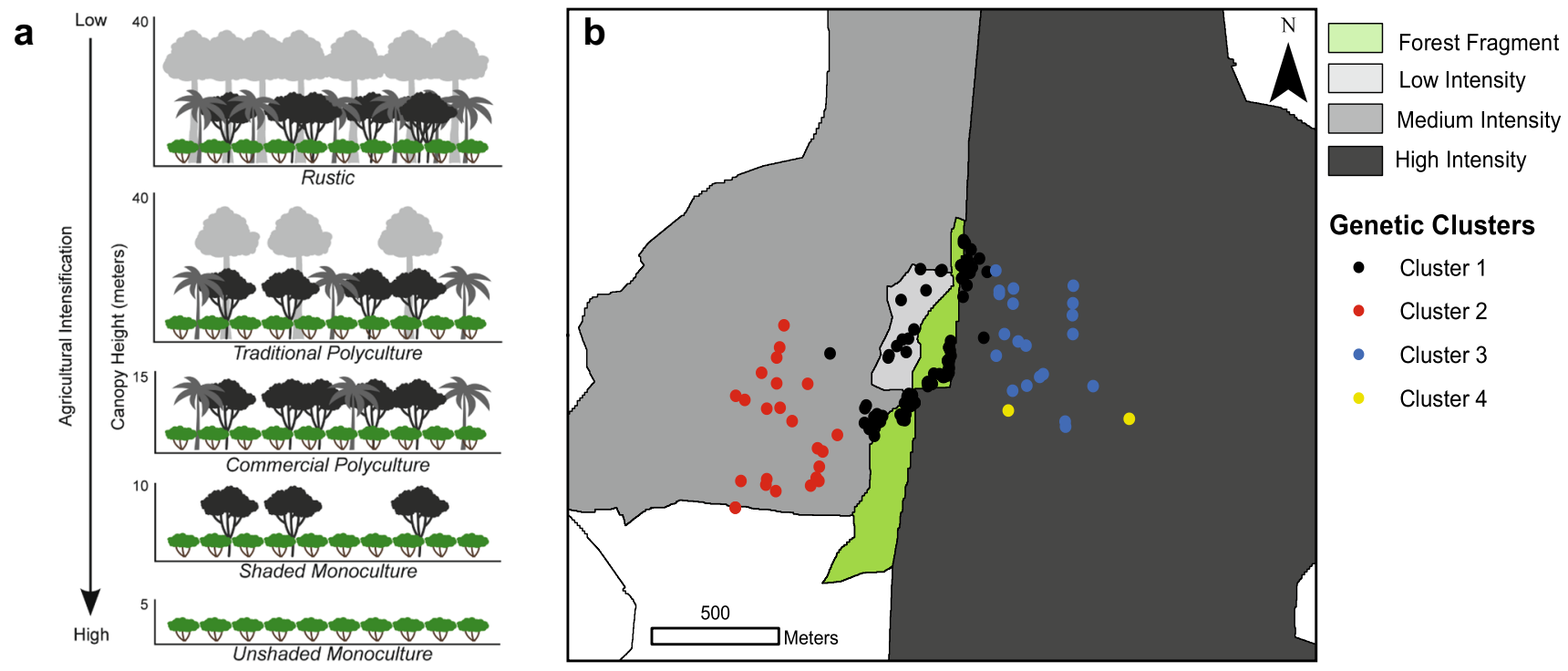

Fig. 1 a Coffee production types based on Moguel and Toledo (1999). b Sampling sites and Geneland clustering results. Each circle represents an individual sampled, and each color represents cluster membership. (Color figure online)

This study aims to increase our knowledge about the historical response of tropical terrestrial small mammals to agricultural intensification and forest fragmentation in a coffee agroecosystem. As common members of the animal community, small mammals play important ecological roles (Lidicker 1975), but may be negatively affected by human-driven landscape modifications (Gibson et al. 2013). Heteromys desmarestianus goldmani, a common rodent in southern Mexico, is known to prefer forested environments (Fleming 1983), and consuming and/or dispersing a variety of seeds in tropical forests (MartinezGallardo and Sanchez-Cordero 1993). This species, a yearlong breeder (Fleming 1983), has a home range of approximately $100 \mathrm{~m}^{2}$. This is a small home range when compared to other groups of small mammals such as Peromyscus spp., with home ranges averaging $2000 \mathrm{~m}^{2}$ (Scheibe 1984).

We studied the effect of different coffee management practices on the population genetic structure of $H$. $d$. goldmani with the goal of addressing the following questions. Can $H$. $d$. goldmani persist in a coffee agricultural matrix? If so, what is the nature of the population structure and does it vary between coffee farms and a forest fragment? Because $H$. $d$. goldmani is a forest specialist, we expect the species to be present in the forest fragment and within coffee farms that are either close to forest edges or within a coffee matrix of high quality (e.g., low management intensity). Additionally, we expect individuals within the forest fragment to show higher connectivity (i.e., less subpopulation genetic differentiation), than those found within the coffee farms.

\section{Materials and methods}

This study was conducted at the Finca Irlanda Research Station located in the tropical montane region of Soconusco in Chiapas, Mexico. The area contains many coffee farms varying in management intensity, ranging from rustic to unshaded monocultures with forest patches scattered between them (Fig. 1b, see Supplementary Material). The age of the farms ranges from 60 to 100 years. Although management practices vary over time, the farms included in this study have had similar management practices for at least 17 years (Perfecto and Vandermeer 2002).

Samples were collected from four sites: one forest fragment and three coffee farms of various management levels that are adjacent to the forest fragment (Fig. 1b). Coffee farms were named after the level of management intensity (i.e., low, medium, and high) based on the Moguel and Toledo (1999) classification system. Our sampling covered an area of approximately $1.6 \mathrm{~km}^{2}$ (see Supplementary Material). Sex and GPS coordinates for each individual sample were recorded (Table S1, Supplementary Material), and DNA extracted from ear tissue samples. Microsatellite primers were designed specifically for $H$. $d$. goldmani by the Savannah River Ecology Laboratory. All samples were genotyped for 11 microsatellite loci (Table S2, Supplementary Information). We estimated relatedness ( $r$ ) within and between sites to: (1) identify siblings and (2) assess bias in dispersal of males and females. We calculated three different relatedness estimators (Ritland 1996; Queller and Goodnight 1989; Lynch and Ritland (1999) using GenAlEx (Peakall and Smouse 2012). 
We estimated the number of genetic units $(\mathrm{K})$ and the locations of breaks in gene flow that delineate these clusters using Geneland 4.0.3 (Guillot et al. 2008), a spatial Bayesian clustering method. The analysis included 20 independent runs, using a range of $\mathrm{K}$ from 1 to 10 . After determining the optimal number of genetic units or populations $(\mathrm{K})$, a separate run was performed for the assignment of individuals (see Supplementary information for details). For the genetic clusters identified by Geneland we measured genetic diversity by quantifying observed heterozygosity $\left(H_{O}\right)$, expected heterozygosity $\left(H_{E}\right)$ and fixation index $\left(F_{I S}\right)$ GenAlEx (Peakall and Smouse 2012). Additionally, we calculated the allelic richness (AR) in ADZE (Szpiech et al. 2008) using, as our sample size, the number of individuals present in the smallest cluster. To assess differences in genetic diversity between clusters we used values for each measure (i.e., $F_{I S}$, $H_{E}, H_{O}, A R$ ) for each locus at each cluster and conducted a bootstrapping analysis of the mean in R 3.2.4 (2016). To assess genetic differentiation between groups we calculated $F_{S T}$ (Wright 1951) using Arlequin (Excoffier and Lischer 2010). We also measured $F_{S T}$ for each sex separately to check for signals of sex biased dispersal.

We examined the correlation between genetic distance and geographic distance (i.e., isolation-by-distance) using Mantel tests (Mantel 1967) as implemented in GenAlEx (Peakall and Smouse 2012). Genetic distances were measured as individual pairwise $a_{r}$ values (Rousset 2000) calculated in Genepop (Rousset 2008). Geographic distances between individuals were calculated with GPS locations using the geographical information system program ArcView version 3.1 (ESRI, California, USA).

\section{Results}

A total of 61 alleles were scored at 11 loci in all H.d. goldmani samples with an average of 7.8 alleles per locus (range 3-13). Primer and locus information is in Table S2 (Supplementary Material). Results for the relatedness estimators (Table S3, Supplementary Material) indicate low relatedness of individuals within and between sampling sites. However, $0.2 \%$ of individual pairs show relatedness values of $>0.25$. Although males appear to have lower levels of relatedness (Table S3, Supplementary Material), we were not able to detect significantly different patterns between males and females from each cluster (Table S6, Supplementary Material). This may be due to the low number of males present in the study, i.e. $11 \%$ of all samples (Table S3, Supplementary Material).

Geneland genetic clustering analysis was done with and without closely related individuals $(r>0.25)$. Results did not change; thus, we present results using all individuals sampled. Genetic structure emerged from Geneland, with a K of 4 as the optimal value in all the 20 runs (Table S4). Geneland assigned most individuals to one of four clusters: (1) Individuals from the forest fragment, low intensity coffee and individuals from medium and high intensity coffee close to the forest edge (Cluster 1; Fig. 1b); (2) individuals from the medium intensity coffee farm (Cluster 2; Fig. 1b); (3) individuals from the high intensity coffee farm (Cluster 3; Fig. 1b); and (4) two individuals from the high intensity coffee farm (Cluster 4; Fig. 1b), suggesting the presence of further structuring in unsampled areas of the farm.

Interestingly, we observed that forest individuals are all assigned to a single cluster regardless of the distance between them (Fig. 1b; North to South). Samples up to $700 \mathrm{~m}$ from each other were assigned to the same cluster. On the other hand, we observe that this pattern does not hold for the medium and high intensity coffee farms where individuals were assigned to different clusters depending on their distance from the forest suggesting some barrier to movement (Fig. 1b; East to West). Individuals as close as $90 \mathrm{~m}$ from each other were assigned to different clusters. Results show no significant difference in genetic diversity measures (i.e. $H_{E}, H_{O}, F_{I S}, A R$ ) among the three major clusters (Supplemental Information Table S5 and Fig. S2). The measure of genetic differentiation, $F_{S T}$ indicated low but significant levels of differentiation between clusters (Table 1; $\mathrm{P}<0.005)$.

A significant, but weak positive relationship was found between genetic distance and geographic distance between all sample pairs $(\mathrm{r}=0.132 ; \mathrm{P}=0.001 ;$ Fig. 2$)$. This result suggests that isolation-by-distance (IBD) explains a small proportion of the observed genetic structure and other landscape factors might be driving the patterns observed in the cluster analyses.

\section{Discussion}

Our results show that $H$. $d$. goldmani can persist within coffee farms and confirm that some population structure exists in this coffee agroecological landscape. Isolation by distance was significant but weak, suggesting that the composition of the agricultural matrix (e.g. vegetation complexity, coffee

Table $1 \quad \mathrm{~F}_{\mathrm{ST}}$ values for Geneland genetic clusters 1-3

\begin{tabular}{llll}
\hline & Cluster 1 & Cluster 2 & Cluster 3 \\
\hline Cluster 1 & 0 & & \\
Cluster 2 & $0.02347^{*}$ & 0 & \\
Cluster 3 & $0.02266^{*}$ & $0.02035^{*}$ & 0 \\
\hline
\end{tabular}

Cluster 4 was not included in this analysis due to the low samples size $(\mathrm{n}=2)$. The asterisk $(*)$ indicates values are statically significant $(\mathrm{P}<0.5)$ 


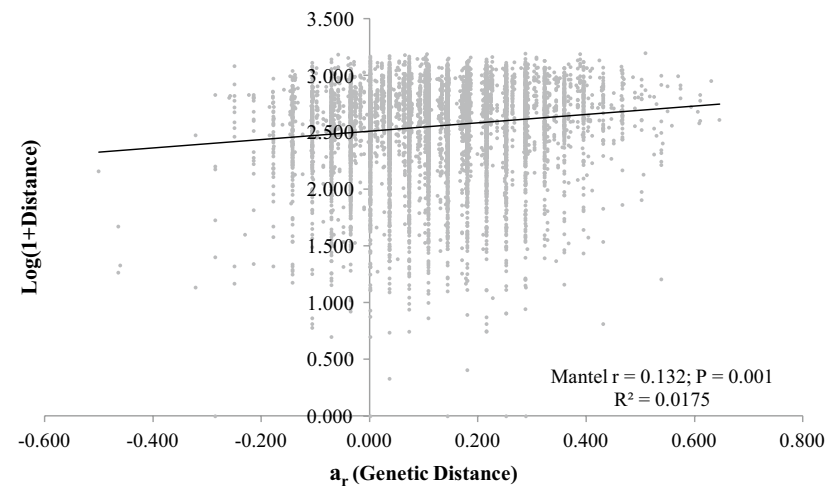

Fig. 2 Regression showing isolation-by-distance results for all pairs of individuals sampled. Each dot represents a pair of individuals and the line represents the best fit for the data

density), could limit gene flow. Resource availability in the coffee farms may explain some of the observed genetic structure. Coffee agroecosystems with low to medium management intensity (e.g., polyculture, shade grown, limited use of pesticides) have a higher vegetation complexity (Moguel and Toledo 1999) and a forest-like understory. In contrast, high intensity coffee agroecosystems present an understory substantially different from a natural forest, raising the question of how $H$. $d$. goldmani, a forest dwelling rodent, can persist in what must be a harsh environment for it. The mountainous landscape in which these farms occur makes some areas inaccessible to production. Farms usually have several steep ravines that are rarely planted or managed. These areas could be serving as small oases providing the resources the mice need to survive, but only in these very local micro habitats.

The literature reports only a few studies that examined the population structure of a heteromyid species (Schmidt et al. 1989; Rios et al. 2016). These studies found small genetic distances between forest populations of Heteromys gaumeri (Schmidt et al. 1989) using protein electrophoresis, and no genetic structure based on mitochondrial DNA for $\mathrm{H}$. nelsoni, (Rios et al. 2016). Both species have a different ecology and distribution than $H$. desmarestianus and may not be directly comparable. Other studies examining the population structure of small mammals in agricultural landscapes have reported a variety of genetic responses to matrix composition and fragmentation (Gauffre et al. 2008; Banks et al. 2005), showing that species responses to the matrix depend on the organism's life history. Generalist small mammal species have been reported to show high levels of connectivity between natural and agricultural lands (Gauffre et al. 2008), while specialist species show the opposite pattern of restricted dispersal (Banks et al. 2005). Our results for $H$. d. goldmani suggest that the coffee agricultural matrix may be permeable enough to facilitate dispersal and gene flow.
However, the degree of permeability varies depending on other landscape characteristics, which could be linked to management practices.

Other studies across many different taxa, including small mammals, have identified natal habitat preference induction (NHPI) as a potential driver of population structure (Davis and Stamps 2004). If this is present in our system, $H$. $d$. goldmani individuals will prefer environments like the one they were born in. In our case, individuals born in either coffee or forest environments would preferentially seek those same conditions, thus reducing gene flow across the landscape (Davis and Stamps 2004).

Considering that a moderately intensified production system, such as the ones included in this study, appears to limit connectivity in $H$. d. goldmani, it is likely that other production practices with higher levels of intensification (e.g., soy bean or maize production) will represent strong barriers to gene flow for forest dwelling small mammals. However, more research is needed in this area to understand the management practices that drive these genetic patterns. Replicating this study in other forest fragments and coffee farms in the area would help us gain a broader understanding of the effects of land use change and fragmentation on small mammal communities at a broader scale. Moving forward, it is important also to understand patterns of connectivity, and more importantly gene flow, among populations in natural continuous landscapes. Finally, our study demonstrates the impact of the agricultural matrix in dispersal of a species and the importance of understanding long-term responses of populations to these changes.

Acknowledgements We would like to thank Dr. Consuelo Lorenzo from El Colegio de la Frontera Sur, San Cristobal for her support in sample collection and Dr. Carlos J. Anderson for his valuable comments on the manuscript and support with statistical analysis. We thank the managers, farmers and owners of Finca Irlanda and Finca Hamburgo in Chiapas, Mexico for allowing us to conduct this study and for their support with fieldwork. BOJ was supported by the following NIH training grant: "Michigan Predoctoral Training in Genetics (T32GM007544)". This study was funded by the International Institute and the Department of Ecology and Evolutionary Biology at the University of Michigan.

\section{Compliance with ethical standards}

Conflict of interest The authors declare that they have no conflict of interest.

Open Access This article is distributed under the terms of the Creative Commons Attribution 4.0 International License (http://creativecommons.org/licenses/by/4.0/), which permits unrestricted use, distribution, and reproduction in any medium, provided you give appropriate credit to the original author(s) and the source, provide a link to the Creative Commons license, and indicate if changes were made. 


\section{References}

Banks SC, Lindenmayer DB, Ward SJ, Taylor AC (2005) The effects of habitat fragmentation via forestry plantation establishment on spatial genotypic structure in the small marsupial carnivore, Antechinus agilis. Mol Ecol 14:1667-1680

Davis JM, Stamps JA (2004) The effect of natal experience on habitat preferences. Trends Ecol Evol 19:411-416

Excoffier L, Lischer HEL (2010) Arlequin suite ver 3.5: a new series of programs to perform population genetics analyses under Linux and Windows. Mol Ecol Resour 10:564-567

Fleming TH (1983) Heteromys desmarestianus. In: Janzen DH (ed) Costa Rican natural history. University of Chicago Press, Chicago, pp 474-475

Frankel O, Soulé ME. (1981) Conservation and evolution. Cambridge University Press Archive, Cambridge

Gauffre B, Estoup A, Bretagnolle V, Cosson JF (2008) Spatial genetic structure of a small rodent in a heterogeneous landscape. Mol Ecol 17:4619-4629

Gibson L, Lynam AJ, Bradshaw CJA, He FL, Bickford DP, Woodruff DS, Bumrungsri S, Laurance WF (2013) Near-complete extinction of native small mammal fauna 25 years after forest fragmentation. Science 341:1508-1510

Guillot G, Santos F, Estoup A (2008) Analysing georeferenced population genetics data with Geneland: a new algorithm to deal with null alleles and a friendly graphical user interface. Bioinformatics 24:1406-1407

Levins R (1969) Some demographic and genetic consequences of environmental heterogeneity for biological control. Bull Entomol Soc Am 15:237-240

Lidicker WZ (1975) The role of dispersal in the demography of small mammals. Small Mamm 5:103-128

Lynch M, Ritland K (1999) Estimation of pairwise relatedness with molecular markers. Genetics 152(4):1753-1766

Manel S, Schwartz MK, Luikart G, Taberlet P (2003) Landscape genetics: combining landscape ecology and population genetics. Trends Ecol Evol 18:189-197

Mantel N (1967) Detection of disease clustering and a generalized regression approach. Cancer Res 27:209-220

Martinez-Gallardo R, Sanchez-Cordero V (1993) Dietary value of fruits and seeds to spiny pocket mice, Heteromys desmarestianus (Heteromyidae). J Mammal 74:436-442
Moguel P, Toledo VM (1999) Biodiversity conservation in traditional coffee systems of Mexico. Conserv Biol 13:11-21

Peakall R, Smouse PE (2012) GenAlEx 6.5: genetic analysis in Excel. Population genetic software for teaching and research-an update. Bioinformatics 28:2537-2539

Perfecto I, Vandermeer J (2002) Quality of agroecological matrix in a tropical montane landscape: ants in coffee plantations in southern Mexico. Conserv Biol 16:174-182

Perfecto I, Vandermeer J (2008) Biodiversity conservation in tropical agroecosystems: a new conservation paradigm. Ann NY Acad Sci 1134:173-200

Perfecto I, Vandermeer J (2015) Coffee agroecology: a new approach to understanding agricultural biodiversity, ecosystem services and sustainable development. Routledge, London

Perfecto I, Vandermeer J, Wright LA (2009) Nature's matrix: linking agriculture, conservation and food sovereignty. Earthscan, Hoboken

Queller DC, Goodnight KF (1989) Estimating relatedness using genetic markers. Evol Int J Org Evol 43(2):258-275

Rios E, Lorenzo C, Álvarez-Castañeda ST (2016) Genetic variation in Heteromys nelsoni (Rodentia: Heteromyidae) reveals its possible natural extinction. Mammalia

Ritland K (1996) Estimators for pairwise relatedness and individual inbreeding coefficients. Genet Res 67:175-185

Rousset F (2000) Genetic differentiation between individuals. J Evol Biol 13:58-62

Rousset F (2008) GENEPOP'007: a complete re-implementation of the GENEPOP software for Windows and Linux. Mol Ecol Resour 8:103-106

Scheibe JS (1984) Sexual differences in the home ranges of Peromyscus truei and Dipodomys-panamintinus (Rodentia). Southwest Nat 29:7-13

Schmidt CA, Engstrom MD, Genoways HH (1989) Heteromys gaumeri. Mammalogy Papers: University of Nebraska State Museum, Lincoln, p 96

Szpiech ZA, Jakobsson M, Rosenberg NA (2008) ADZE: a rarefaction approach for counting alleles private to combinations of populations. Bioinformatics 24(21):2498-2504

Wright S (1951) The genetical structure of populations. Ann Eugenics $15: 323-354$ 